\title{
AMENDMENTS
}

\section{Publisher Correction: Death by inflammation: drug makers chase the master controller}

Cormac Sheridan

Correction to: Nature Biotechnology https://doi.org/10.1038/s41587-019-0023-4, published online 4 February 2019.

In the version of this article initially published, a GlaxoSmithKline compound referred to as GSK298559 was listed in Table 1 as a RIPK1 inhibitor in phase 1 trials for inflammatory bowel disease. The correct designation is GSK2983559; however, this compound is a RIPK2 inhibitor and thus should not have been included in the table in question. The table row has been deleted. The error has been corrected in the HTML and PDF versions of the article.

Published online: 6 March 2019

https://doi.org/10.1038/s41587-019-0082-6

\section{Publisher Correction: Federated discovery and sharing of genomic data using Beacons}

Marc Fiume, Miroslav Cupak, Stephen Keenan, Jordi Rambla, Sabela de la Torre, Stephanie O. M. Dyke, Anthony J. Brookes (D, Knox Carey, David Lloyd, Peter Goodhand, Maximilian Haeussler, Michael Baudis D, Heinz Stockinger, Lena Dolman, Ilkka Lappalainen, Juha Törnroos, Mikael Linden (D), J. Dylan Spalding (D), Saif Ur-Rehman, Angela Page, Paul Flicek (D), Stephen Sherry, David Haussler, Susheel Varma (D), Gary Saunders and Serena Scollen

Correction to: Nature Biotechnology https://doi.org/10.1038/s41587-019-0046-x, published online 4 March 2019.

In the version of this article initially published, Lena Dolman's second affiliation was given as Wellcome Trust Sanger Institute, Wellcome Genome Campus, Hinxton, Cambridge, UK. The correct second affiliation is Ontario Institute for Cancer Research, Toronto, Ontario, Canada. The error has been corrected in the HTML and PDF versions of the article.

\section{Publisher Correction: CRISPR target prediction remains blunt tool for clinical applications} John Hodgson

Correction to: Nature Biotechnology https://doi.org/10.1038/s41587-019-0057-7, published online 4 March 2019.

In the version of this article initially published, we reported that Sangamo's SB-318 had failed to change baseline leukocyte $\alpha$-L-iduronidase in a phase $1 / 2$ trial. The drug failed to change baseline plasma $\alpha$-L-iduronidase but did increase leukocyte $\alpha$-L-iduronidase to within the normal range. The error has been corrected in the HTML and PDF versions of the article.

Published online: 20 March 2019

https://doi.org/10.1038/s41587-019-0107-1 